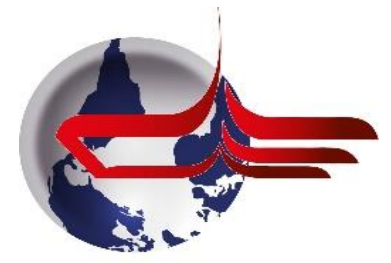

Turkish Journal of Educational Studies, 6 (1) Ocak $2019 \quad$ Research Article / Araştırma Makalesi

Article İnfo/Makale Bilgisi

Received/Geliş: 03 Aralık 2018

Accepted/Kabul: 5 Ocak 2019

\title{
4. Sınıf Matematik Öğretmen Adaylarının, İyi Bir Matematik Öğretmeninin Özelliklerine Yönelik Görüşlerinin İncelenmesi Ebru KÜKEY*
}

Tayfun TUTAK**

\section{Öz}

Bu çalışmada, matematik öğretmeninin özellikleri 4. sınıf matematik öğretmen adaylarına göre araştırılmıştır. Öğretmen adaylarının bilgilerinin ayrıntılı incelenmesi amaçlandığından araştırmada nitel araştırma yöntemlerinden durum çalışması kullanılmıştır. Çalışma grubunu, 39'u kadın, 11'i erkek olmak üzere toplam 50, 4. sınıf matematik öğretmen adayı oluşturmaktadır. Öğretmen adaylarıyla yapılandırılmış görüşmeler aracılığıyla elde edilen veriler, içerik analizi ile analiz edilmiştir. Verilerin analiz edilmesiyle temalar ve temaların alt boyutları belirlenmiştir. Bu doğrultuda derse yönelik tutum, kişisel özellikler, alan bilgisi ve meslek bilgisi temaları elde edilmiştir. Temaların özellikleri dikkate alındığında derse yönelik tutum teması altında dersi ve matematiği sevdirme özelliklerinin ön plana çıktığ 1 belirlenmiştir. Kişisel özellikler temasında kendini sevdirme, kendini geliştirme, arkadaş gibi olma, mesleğini sevme, öğrencileri anlama ve güler yüzlü olma gibi özelliklerin olduğu sonucuna ulaşılmıştır. Alan bilgisi temasına yönelik olarak günlük yaşamla ilişki kurma ve alanında uzman olma özelliklerinin ön plana çıktığı tespit edilmiştir. Meslek bilgisi temasında ise öğrencilerin hazır bulunuşluk düzeylerini dikkate alma, materyal kullanma, olumsuz ön yargıyı kaldırma, sınıfa hâkim olma, soyut kavramları somutlaştırabilme, derse hazırlık yaparak gelme, dersi eğlenceli hale getirme, diğer derslerle ilişkilendirme gibi özelliklerinin olduğu sonucuna ulaşılmıştır. Bu özellikleri dikkate alarak yapılan eğitim öğretimin, öğrencilerin daha etkili öğrenmelerini sağlamada oldukça faydalı olacağı düşünülmektedir.

Anahtar Kelimeler: Matematik, Matematik Öğretmen Adayı, Öğretmen Nitelikleri.

\section{Investigation of the Views of 4th Grade Pre-service Mathematics Teachers on the Characteristics of A Good Mathematics Teachers}

\begin{abstract}
In this study, the characteristics of mathematics teacher were investigated according to the 4th grade pre-service mathematics teachers. As it is aimed to examine the thoughts of pre-service teachers was used a case study of qualitative research methods. The study group consisted of 50 pre-service mathematics teachers 39 female and 11 male. The data obtained through from pre-service teacher with structured interviews were analyzed by content analysis. Themes and the sub-dimensions of themes were determined with analyzing the data. In this context, attitudes towards the course, personal characteristics, field knowledge and professional knowledge themes were obtained.

As a result considering the characteristics of the themes, it was determined that the lesson and mathematics loving features came to the forefront under the theme of attitude towards the lesson. In the theme of personal characteristics; self-loving, self-development, being like the profession, understanding the students and have been found to be friendly features. It has been determined that features of associating with the daily life and being expert in the field come to the forefront in the field information theme. In the subject of professional knowledge, it is
\end{abstract}


concluded that students have characteristics such as taking into consideration the readiness levels, using materials, eliminating the negative prejudice, a dominate the class, embodying the abstract concepts, making the lesson fun and associating with other lessons. Considering of these characteristics done training will be very useful in ensuring that students learn more effectively.

Keywords: Mathematics, Pre-service Mathematics Teachers, Teacher Qualifications.

* Arş. Gör. Dr. Fırat Üniversitesi, Eğitim Fakültesi, Matematik ve Fen Bilimleri Eğitimi Bölümü, Elazı̆̆, Türkiye, ekukey@firat.edu.tr

${ }_{* *}$ Dr. Öğr. Üyesi Fırat Üniversitesi, Eğitim Fakültesi, Matematik ve Fen Bilimleri Eğitimi Bölümü, Elazığ, Türkiye, tavfuntutak@hotmail.com

\section{GIRIŞ̧}

Günümüzde teknolojik, bilimsel, toplumsal, ekonomik olmak üzere pek çok alanda hızlı gelişim ve değişimlerin yaşanması, eğitim öğretim sürecinde de gelişim ve değişimlerin yaşanmasını gerektirmektedir (Arslan \& Özpınar, 2008). Bu çerçevede eğitim öğretim sürecinde öğrencilerin bilgiyi kullanabildikleri, yaşam şartlarında uygulayabildikleri durumların önem kazandığı söylenebilir.

Günümüzde, sürekli kendisini yenileyen yani yaşam boyu öğrenmeyi gerçekleştiren, gelişmeleri takip eden, değişime ayak uydurabilen ve bilinçli bir bilgi tüketicisi olmakla beraber bilgiyi üretebilen bireylere ihtiyaç duyulmaktadır (Akkoyunlu \& Kurbanoğlu, 2003). Bu çerçevede; günümüz insanları üretken, hızlı düşünen, öğrenmesi gereken bilgiyi bilen, daha kolay öğrenebilmenin yollarının farkında olan yani kendini iyi bilen, çok bilgiye değil gereksinim duyduğu bilgiye rahatlıkla ulaşabilen ve teknolojiyi kullanabilen bireyler olarak düşünülmektedir (Umay, 2004). Bireylerin bu şekilde yetiştirilmesinde öğretmenlere büyük görevler düştüğü söylenebilir. Öğretmenlerin ne tür özelliklere sahip olmaları ise burada büyük öneme sahip olduğu ifade edilebilir.

Matematiğin özellikleri incelendiğinde matematik dersinin; öğrencilere günlük yaşamda gerekli olan bilgi ve becerileri kazandırmak, problem çözmeyi öğretmek, günlük hayatta karşılaşılan olaylarda problem çözme sürecinde bulunan düşünme biçimlerini kazandırmak ve geleceğe hazırlamak için etkili ve gerekli olan yapılardan birisi olduğu görülmektedir (Yıldırım, 2006). Matematik öğrenimi ve öğretimini etkileyip yön veren en önemli bileşenlerden birinin öğretmen olduğu kabul edilmektedir. İyi bir öğretmenin özellikleri arasında alan bilgisinin oldukça etkili bir rol oynadığı bilinmektedir. Ancak sadece alan bilgisi etkili bir öğretim için yeterli olmadığı, bununla beraber öğretmenlerin bildiklerinin yanında bunları nasıl öğreteceklerinin de önemli bir yeri vardır (Shulman, 1986). Hiebert, Morris ve Glass (2003) matematik öğretmen adaylarının matematiksel alan yeterliliğine sahip olmak ve öğretmeye yönelik olarak bilgi, beceri ve eğilimleri geliştirmek olmak üzere iki temel amaç doğrultusunda yetiştirilmesi gerektiğini belirtmişlerdir. Bu kapsamda Lansdell (1999), matematik öğretmenlerinin matematiksel bilgilerinin geliştirilmesiyle birlikte matematiği nasıl öğreteceklerine yönelik olarak öğretmenlik becerilerinin de geliştirilmesine yönelik olarak çalışmaların yapılması gerektiğini ifade etmiştir. Günümüzde matematik öğretmenlerinin eğitim öğretime yönelik olarak ne tür özelliklere sahip olmaları gerektiğine yönelik olarak bazı araştırmaların yapıldığı görülmektedir (Alkan, Köroğlu \& 
Başer, 1999; Kyriacou \& Coulthard, 2000; Baki \& Gökçek, 2007; Arslan \& Özpınar 2008; Kükey \& Aslaner, 2017).

Literatür incelendiğinde matematiğin öğretiminde, öğretmenlerin yerinin önemli olduğu görülmektedir. Öğretmenlerin sahip olması gereken özelliklerin alan bilgisinin yanında nasıl öğreteceklerinin üzerinde de durulması gerektiğinin önemi vurgulanmaktadır (Shulman, 1987; Özabacı \& Acat, 2005; Iossi, 2007). Bu kapsamda, öğretmenlerin sahip olması gereken özelliklerinin neler olmas1 gerektiğine yönelik olarak öğretmen adaylarının düşüncelerinin incelenmesinin eğitim sürecine olumlu katkılar sağlayacağı düşünülmektedir (Kükey \& Aslaner, 2017). Bu nedenle yapılan bu çalışmada 4. sınıf matematik öğretmen adaylarına göre iyi bir matematik öğretmenin özelliklerinin neler olması gerektiği incelenmiştir.

\section{YÖNTEM}

\subsection{Araştırmanın Modeli}

$\mathrm{Bu}$ araştırma, öğretmen adaylarının düşüncelerinin derinlemesine incelenmesi olarak tasarlandığından araştırmanın modeli, nitel araştırma yöntemlerinden durum çalışması olarak belirlenmiştir. Nitel durum çalışmalarının en belirgin özelliği bir ya da birkaç durumun derinlemesine incelenerek araştırılmasıdır. Yani belirli bir duruma yönelik olarak etkenler bütüncül bir yaklaşımla araştırılıp ilgili durumu nasıl etkiledikleri ve ilgili durumdan nasıl etkilendikleri üzerinde durulmuaktadır (Yıldırım \& Şimşek, 2011).

Araştırmanın çalışma grubu, amaçlı örnekleme yöntemlerinden kolay ulaşılabilir örnekleme yöntemiyle belirlenmiştir. Bu kapsamda çalışma grubunu 2017-2018 öğretim y1lında bir devlet üniversitesinin ilköğretim matematik öğretmenliği programı 4. sınıfında öğrenim gören 50 öğretmen adayı oluşturmaktadır. Gönüllü katılıma dayalı olarak belirlenen öğretmen adaylarının özellikleri aşağıdaki tabloda verilmiştir.

Tablo 1. Öğretmen Adaylarının Özellikleri

\begin{tabular}{cccccc}
\hline Kod & Sinıfi & Cinsiyet & Kod & Sinıfi & Cinsiyet \\
\hline Ö1 & 4 & Erkek & Ö26 & 4 & Erkek \\
Ö2 & 4 & Kadın & Ö27 & 4 & Kadın \\
Ö3 & 4 & Kadın & Ö28 & 4 & Kadın \\
Ö4 & 4 & Kadın & Ö29 & 4 & Kadın \\
Ö5 & 4 & Kadın & Ö30 & 4 & Kadın \\
Ö6 & 4 & Kadın & Ö31 & 4 & Kadın \\
Ö7 & 4 & Kadın & Ö32 & 4 & Kadın \\
Ö8 & 4 & Erkek & Ö33 & 4 & Kadın \\
Ö9 & 4 & Erkek & Ö34 & 4 & Kadın \\
Ö10 & Kadın & Ö35 & 4 & Kadın \\
Ö11 & 4 & Kadın & Ö36 & 4 & Kadın \\
Ö12 & 4 & Kadın & Ö37 & 4 & 4 \\
Ö13 & 4 & Erkek & Ö38 & &
\end{tabular}




\begin{tabular}{llllll}
\hline \hline Ö14 & 4 & Erkek & Ö39 & 4 & Erkek \\
Ö15 & 4 & Erkek & Ö40 & 4 & Kadın \\
Ö16 & 4 & Erkek & Ö41 & 4 & Kadın \\
Ö17 & 4 & Kadın & Ö42 & 4 & Kadın \\
Ö18 & 4 & Kadın & Ö43 & 4 & Kadın \\
Ö19 & 4 & Erkek & Ö44 & 4 & Kadın \\
Ö20 & 4 & Kadın & Ö45 & 4 & Kadın \\
Ö21 & 4 & Kadın & Ö46 & 4 & Kadın \\
Ö22 & 4 & Kadın & Ö47 & 4 & Kadın \\
Ö23 & 4 & Erkek & Ö48 & 4 & Kadın \\
Ö24 & 4 & Kadın & Ö49 & 4 & Kadın \\
Ö25 & 4 & Kadın & Ö50 & 4 & \\
\hline
\end{tabular}

Tablo incelendiğine öğretmen adaylarından 39'unun kadın olduğu, çalışma grubunun ise \%78'ini temsil ettiği belirlenmiştir. Çalışma grubunda bulunan erkeklerin ise 11 olduğu, çalışma grubunun \%22'sini oluşturduğu görülmektedir.

\subsection{Veri Toplama Araçları ve Verilerin Analizi}

Öğretmen adaylarının görüşlerini belirlemek için "Matematik Öğretmen Adayına Yönelik Görüş Formu" hazırlanmış ve bu formda "Matematik öğretmeni sizce nasıl olmalıdır?" şeklinde açık uçlu soruyla öğretmen adaylarının düşüncelerini belirtmeleri istenmiştir. Uygulanma yapılmadan önce 5 matematik öğretmen adayıyla görüşmeler yapılmıştır. Bu görüşmelerde çalışmanın ne kadar süreceği belirlenmiş ve bunun yanında araştırmacının deneyim kazanması sağlanmıştır. Gerekli düzenlemeler sonrasında asıl çalışma yapılmıştır. Öğretmen adaylarına düşüncelerinin gizli tutulacağı, çalışma dışında herhangi bir yerde kullanılmayacağı, bu kapsamda görüşlerini samimi olarak belirtmeleri gerektiği ifade edilmiştir.

Çalışmada elde edilen veriler içerik analiziyle incelenmiştir. İçerik analizi, birbirine benzeyen verileri belirli kavramlar çerçevesinde bir araya getirmek ve elde edilen temaları okuyucunun anlayabileceği biçimde düzenleyerek yorumlamaktır (Yıldırım \& Şimşek, 2011). Verilerin analizi sürecinde öğretmen adayları Ö1, Ö2 şeklinde kodlanmıştır. Veriler, iki bağımsız araştırmacı tarafından kodlanıp kodlamalar arasındaki uyum düzeyi belirlenmiştir. Verilerin uyum düzeyi Miles ve Huberman (1994)'1n ifade ettiği güvenirlik formülüyle incelenmiştir. Bu kapsamda araştırmacıların yapmış oldukları kodlamalar arasındaki uyum düzeyi \%87 olarak bulunmuştur. Bunun yanında farklı olarak kodlanan tema ve kavramlar, araştırmacıların ortak görüşüyle değerlendirilmiştir.

\section{BULGULAR}

Çalışmadan elde edilen veriler doğrultusunda, ilköğretim matematik öğretmenliği programı 4. sınıf öğrencilerine göre iyi bir matematik öğretmenin özellikleri 4 tema altında belirlenmiştir. $\mathrm{Bu}$ temalar; derse yönelik tutumları, kişisel tutumları, alan bilgisi ve mesleki bilgisi olarak ifade edilmiştir. 


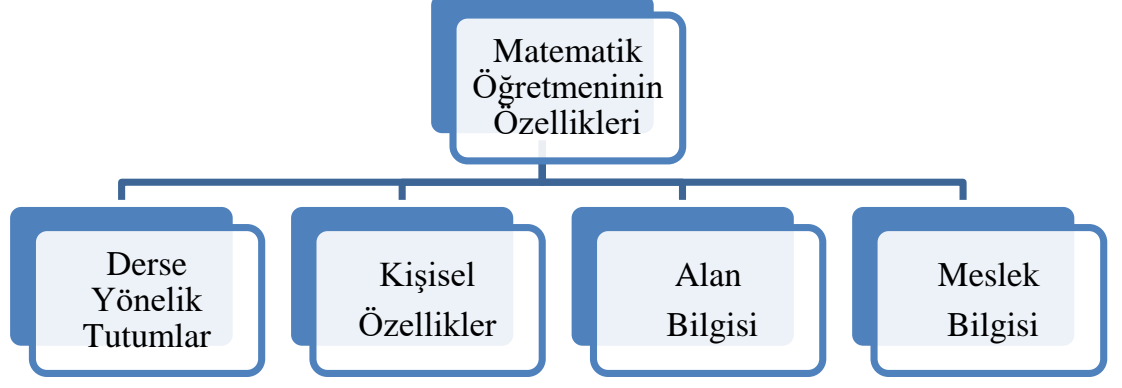

Şekil 1. Matematik Öğretmeninin Özellikleri-Alt Boyutları

\subsection{Derse Yönelik Tutumlar Temasına Yönelik Bulgular}

“Derse yönelik tutumlar” teması altında öğretmen adaylarının ifade etmiş oldukları nitelikler aşağıdaki tabloda verilmiştir.

Tablo 2. Tema 1-Derse Yönelik Tutumlar

\begin{tabular}{llc}
\hline Özellikler & Öğretmen Aday1 Kodları & Frekans \\
\hline Dersi sevdirmeli & Ö7, Ö11, Ö15, Ö16, Ö20, Ö21, Ö35, Ö36 & 8 \\
Matematiği sevdirmeli & Ö5, Ö6, Ö8, Ö10, Ö11, Ö29 & 6 \\
Zor bir ders olduğunun farkında olmalı & Ö6, Ö8, Ö15, Ö24, Ö41 & 5 \\
\hline
\end{tabular}

Öğretmen adaylarının derse yönelik tutumları incelendiğinde en çok, dersi öğrencilere sevdirmenin 8 öğretmen adayı tarafından ifade edildiği görülmektedir. Matematiği sevdirmeli ifadesini 6 öğretmen adayının, zor bir ders olduğunun farkında olmalı ifadesini ise 5 öğretmen adayının kullandığ tespit edilmiştir. Bu kapsamda bazı öğretmen adaylarının görüşleri şu şekildedir.

"Öğrencilere ilk olarak dersi sevdirmeli, matematiğe karşı olumlu bir tavır takınmalarını să̆lamalıdır.” (Ö35)

"Öğrencilerin matematikten nefret etmemeleri aksine ögrencilerin matematiği sevmeleri sağlanmalıdır.” (Ö8)

"Matematiğin toplum nazarında zor bir ders olarak görünmesinden dolayı diğer derslere oranla öğretmenlere dersi sevdirme konusunda extra iş düşmektedir. ” (Ö15)

\subsection{Kişisel Özellikler Temasına Yönelik Bulgular}

"Kişisel özellikler" teması altında öğretmen adaylarının ifade etmiş oldukları nitelikler aşağıdaki tabloda verilmiştir.

Tablo 3. Tema 2-Kişisel Özellikleri

\begin{tabular}{llc}
\hline Özellikler & Öğretmen Aday1 Kodlar1 & Frekans \\
\hline \multirow{2}{*}{ Kendini sevdirmeli } & Ö4, Ö5, Ö7, Ö11, Ö12, Ö16, Ö20, Ö21, Ö38, & 14 \\
& Ö46, Ö47, Ö48, Ö49, Ö50 \\
& 22 & \\
\hline \hline
\end{tabular}




\begin{tabular}{|c|c|c|}
\hline Kendini geliştirmeli (her yönden) & $\begin{array}{l}\text { Ö3, Ö13, Ö21, Ö29, Ö33, Ö34, Ö40, Ö41, } \\
\text { Ö43, Ö44, Ö46 }\end{array}$ & 11 \\
\hline Arkadas gibi olmalı & Ö3, Ö14, Ö24, Ö27, Ö29, Ö32, Ö33, Ӧ35, Ö47 & 9 \\
\hline Mesleğini sevmeli & Ö6, Ö8, Ö10, Ö13, Ö19, Ö34, Ö45, Ö47, Ö50 & 9 \\
\hline Vatan bilinci oluşturmalı & Ö12, Ö26, Ö27, Ö29, Ö35, Ö39, Ö42 & 7 \\
\hline Öğrencileri sevmeli & Ö10, Ö11, Ö24, Ö27, Ö31, Ö46, Ö50 & 7 \\
\hline Öğrencileri anlamalı & Ö12, Ö21, Ö30, Ö34, Ö35, Ö41, Ö47 & 7 \\
\hline Öğrencilerle empati kurabilmeli & Ö5, Ö6, Ö7, Ö9, Ö13, Ö14, Ö47 & 7 \\
\hline Öğrencilerle iletişim kurmalı & Ö23, Ö25, Ö32, Ö42, Ö47, Ö50 & 6 \\
\hline Güler yüzlü olmalı & Ö6, Ö24, Ö25, Ö27, Ö35, Ö49 & 6 \\
\hline İyi bir model olmalı & Ö5, Ö9, Ö28, Ö30, Ö35, Ö39 & 6 \\
\hline Mesleğinin bilincinde olmalı & Ö10, Ö13, Ö36, Ö42 & 4 \\
\hline Öğrencileri hayata hazırlamalı & Ö9, Ö24, Ö28, Ö37 & 4 \\
\hline Katı olmamalı & Ö14, Ö17, Ö19, Ö24 & 4 \\
\hline Öğrenciler arasında adil olmalı & Ö5, Ö17, Ö33, Ö44 & 4 \\
\hline Öğgrencilerin gururunu kırmamalı & Ö4, Ö9, Ö21, Ö33 & 4 \\
\hline Çağın gereksinimlerine ayak uydurmalı & Ö19, Ö26, Ö44, Ö50 & 4 \\
\hline Ö̆ğrencilere özgüven aşılamalı & Ö18, Ö28, Ö32 & 3 \\
\hline Öğrencilerle belirli düzeyde ilişki kurmalı & Ö18, Ö40, Ö47 & 3 \\
\hline Sabırlı olmalı & Ö21, Ö33, Ö48 & 3 \\
\hline Anlayısslı olmalı & Ö25, Ö33, Ö35 & 3 \\
\hline Hayat rehberi olmalı & Ö14, Ö15 & 2 \\
\hline Matematiği sevmeli & Ö24, Ö31 & 2 \\
\hline İyi bir birey yetiştirmeli & Ö33, Ö47 & 2 \\
\hline Aileyle işbirliği içinde olmalı & Ö6, Ö15 & 2 \\
\hline İnsanları sevmeli & Ö35, Ö45 & 2 \\
\hline Öğrencileri dinlemeli & Ö47, Ö50 & 2 \\
\hline Okulla issbirliği içinde olmalı & Ö6 & 1 \\
\hline Ders dışında da öğrencilerin sorunlarını gidermeli & Ö3 & 1 \\
\hline Ahlaklı ve erdemli olmalı & Ö50 & 1 \\
\hline İnsani ilişkileri gelişmiş olmalı & Ö13 & 1 \\
\hline Öğrencilerin hayal dünyasını geliștirmeli & Ö30 & 1 \\
\hline İnsana değer vermeli & Ö32 & 1 \\
\hline İyi bir gözlemci olmalı & Ö32 & 1 \\
\hline Eleştiriye açık olmalı & Ö40 & 1 \\
\hline Kendini iyi ifade edebilmeli & Ö40 & 1 \\
\hline Öğrencilere değerli olduklarını hissettirmeli & Ö47 & 1 \\
\hline
\end{tabular}

$\mathrm{Bu}$ tema altındaki özellikler incelendiğinde öğretmen adaylarının en çok olarak öğrencilere kendilerini sevdirmeleri gerektiğini ifade ettikleri görülmektedir. Daha sonra ise kendilerini geliştirmeleri, öğrencilerle arkadaş gibi olmaları ve mesleklerini sevmeleri gerektiği belirlenmiştir. Bunun yanında öğretmen adaylarının öğrencileri anlamaları, iyi bir model olmalı, öğrencileri sevmeleri, öğrencilerle empati kurmaları, öğrencilerle iletişim kurmaları, güler yüzlü olmaları şeklinde özellikleri ifade ettikleri görülmüştür. Ayrıca mesleğinin bilincinde olmalı, çağın gereksinimlerine ayak uydurabilmeli, sabırlı, anlayışı olmalı, eleştiriye açık ve iyi bir gözlemci olmalı gibi ifadeleri de kullandıkları belirlenmiştir. Bu kapsamda bazı öğretmen adaylarının görüşleri şu şekildedir.

“Olumsuz önyargıları kırmalıdır. Bunu da kendini öğrencilere sevdirerek yapabilir. Öğrenci sevdiği bir öğretmenin dersine ne olursa olsun katılmak ister. Derse karşı bir önyargısı olsa bile ögretmenin bulunduğu ortamda bulunmak ister. ” (Ö16) 
"Öğrencilerle arkadaş gibi olan öğretmenlere öğrenciler daha sevgi dolu ve saygil olurlar. Bunlar sayesinde de o derse verdikleri önem artar." (Ö47)

"Öncelikle mesleğimizi sevmeli ve bu işi hakkayla yapabilmek için çaba sarf etmeli, yenilik ve değişimlere açık olmalıyız." (Ö34)

"Matematiği öğreten ögretmen, kendi ögrencilik yıllarını unutmamış ve hala o günleri hatırlayan bir kişilikte olmalıdır. Çünkü bu durum onun öğrencileriyle daha iyi empati kurmasını sağlar. Empati kurma yeteneği ne kadar gelişmis olursa o derece öğrencilerinin hatalarının kaynaklandiğ sebepleri anlar ve bu duruma bir çözüm bulmaya çalışır.” (Ö13)

“Öncelikle öğretmenlik yapacak kişinin çă̆ın gereksinimlerine ayak uyduran, yenilikçi biri olması gerekir." (Ö19)

\subsection{Alan Bilgisi Temasına Yönelik Bulgular}

"Alan bilgisi” teması altında öğretmen adaylarının ifade etmiş oldukları nitelikler aşağıdaki tabloda verilmiştir.

Tablo 4. Tema 3-Alan Bilgisi

\begin{tabular}{llc}
\hline Özellikler & Öğretmen Aday1 Kodlar1 & Frekans \\
\hline \multirow{3}{*}{ Günlük yaşamla ilişki kurmalı } & Ö1, Ö3, Ö5, Ö7, Ö8, Ö10, Ö11, Ö12, Ö16, Ö18, Ö22, & \\
& Ö23, Ö24, Ö25, Ö28, Ö31, Ö34, Ö35, Ö37, Ö38, Ö40, & 25 \\
Alanında uzman olmalı & Ö42, Ö43, Ö49, Ö50 & \\
Konu bilgisi yüksek olmal1 & Ö3, Ö10, Ö13, Ö17, Ö25, Ö29, Ö41, Ö42, Ö43, Ö44 & 10 \\
\hline
\end{tabular}

Alan bilgisi temasına yönelik olarak en fazla olarak günlük yaşamla ilişki kurma özelliğinin 25 öğretmen adayı tarafından ifade edildiği tespit edilmiştir. Bunun yanında 10 öğretmen adayı matematik öğretmenin alanında uzman olması gerektiğini ifade ettikleri görülmektedir. 3 öğretmen adayı ise matematik öğretmenlerinin konu bilgilerinin yüksek olması gerektiğini belirtikleri tespit edilmiştir. $\mathrm{Bu}$ kapsamda bazı öğretmen adaylarının görüşleri şu şekildedir.

"Matematikte öğrencilerin zorlanmalarının en büyük sebeplerinden olan matematiksel bilgilerin günlük hayatla bir ilişki kurulamamasıdır. Bu yüzden ögrencilerin, hocam bu bizim ne işimize yarayacak ki demesine zemin hazırlamadan gerekli açılklamaları yapıp onları tatmin etmek son derece önemlidir." (Ö1)

“Öncelikle kendini bilen ve alanında yeterli donanıma sahip olmalıdır.”(Ö44)

"Matematik öğretmeninin öncelikle konu bilgisi yüksek olmalıdır. Konu hakimiyetinde ve kendini elinden geldiğince geliştirmeli." (Ö15) 


\subsection{Meslek Bilgisi Temasına Yönelik Bulgular}

"Meslek bilgisi" teması altında öğretmen adaylarının ifade etmiş oldukları nitelikler aşağıdaki tabloda verilmiştir.

Tablo 5. Tema 4-Meslek Bilgisi

\begin{tabular}{|c|c|c|}
\hline Özellikler & Öğretmen Adayı Kodları & Frekans \\
\hline $\begin{array}{l}\text { Öğrencilerin hazır bulunuşluk düzeylerini dikkate } \\
\text { almalı }\end{array}$ & $\begin{array}{l}\text { Ö4, Ö8, Ö13, Ö18, Ö19, Ö20, Ö21, Ö23, Ö29, } \\
\text { Ö31, Ö34, Ö40, Ö41, Ö45 }\end{array}$ & 14 \\
\hline Materyal kullanmalı & $\begin{array}{l}\text { Ö3, Ö4, Ö5, Ö10, Ö18, Ö20, Ö21, Ö31, Ö34, } \\
\text { Ö35, Ö44, Ö45 }\end{array}$ & 12 \\
\hline Olumsuz önyargıyı kaldırmalı & $\begin{array}{l}\text { Ö7, Ö10, Ö16, Ö18, Ö21, Ö24, Ö28, Ö29, } \\
\text { Ö31, Ö42, Ö43, Ö45 }\end{array}$ & 12 \\
\hline Uygun yöntemlerle dersi anlatmalı & $\begin{array}{l}\text { Ö3, Ö4, Ö10, Ö16, Ö19, Ö25, Ö29, Ö39, Ö40, } \\
\text { Ö44 }\end{array}$ & 10 \\
\hline Sinıfa hakim olmalı & Ö3, Ö5,Ö14, Ö15, Ö16, Ö20, Ö25, Ö38, Ö44 & 9 \\
\hline Derse aktif katılımı sağlamalı & Ö1, Ö3, Ö10, Ö12, Ö20, Ö21, Ö29, Ö34, Ö45 & 9 \\
\hline Soyut kavramları somutlaştırabilmeli & $\begin{array}{l}\text { Ö20, Ö21, Ö23, Ö24, Ö28, Ö29, Ö33, Ö39, } \\
\text { Ö40 }\end{array}$ & 9 \\
\hline Öğrencilerin kişisel özelliklerini bilmeli & Ö4, Ö5, Ö11, Ö13, Ö14, Ö17, Ö19, Ö25, Ö28 & 9 \\
\hline Bireysel farklılıkları dikkate almalı & Ö3, Ö4, Ö12, Ö23, Ö30, Ö32, Ö35, Ö43 & 8 \\
\hline Bildiklerini öğrencilere anlatabilmeli & Ö3, Ö7, Ö17, Ö18, Ö22, Ö38, Ö43 & 7 \\
\hline Etkinlik yapmalı & Ö1, Ö5, Ö6, Ö21, Ö25, Ö31, Ö35 & 7 \\
\hline Yaparak-yaşayarak öğretmeli & Ö5, Ö11, Ö25, Ö28, Ö31, Ö40 & 6 \\
\hline Yalın, sade, anlaş1ır bir dil kullanmalı & Ö6, Ö7, Ö12, Ö21, Ö24, Ö33 & 6 \\
\hline Ezbere bağlı kalmamalı & Ö11, Ö18, Ö22, Ö25, Ö29, Ö49 & 6 \\
\hline Örneklerle konuyu pekiştirmeli & Ö12, Ö21, Ö32, Ö33, Ö34 & 5 \\
\hline Bütün öğrencileri derse katmalı & Ö4, Ö14, Ö27, Ö44, Ö49 & 5 \\
\hline Öğrencilerde çalıșma isteği uyandırmalı & Ö7, Ö16, Ö17, Ö35, Ö40 & 5 \\
\hline Dersi eğlenceli hale getirmeli & Ö6, Ö19, Ö35, Ö44, Ö45 & 5 \\
\hline Derse hazırlık yaparak gelmeli & Ö9, Ö20, Ö23, Ö40 & 4 \\
\hline Öğrenci psikolojisinden anlamalı & Ö19, Ö22, Ö41, Ö43 & 4 \\
\hline Basitten karmaşı̆̆a doğru dersi anlatmalı & Ö21, Ö28, Ö38, Ö41 & 4 \\
\hline Konunun mantığını anlatmalı & Ö4, Ö22, Ö29, Ö49 & 4 \\
\hline Nasıl problem çözüleceğini öğretmeli & Ö2, Ö8, Ö18 & 3 \\
\hline $\begin{array}{l}\text { Öğrencilerin ilgi ve isteklerini göz önünde } \\
\text { bulundurmalı }\end{array}$ & Ö16, Ö24, Ö43 & 3 \\
\hline Eğitici oyunlar oynatmalı & Ö20, Ö31, Ö40 & 3 \\
\hline Öğrencilere dönütler vermeli & Ö23, Ö34 & 2 \\
\hline Motive edici kısa hikayeler anlatmalı & Ö4, Ö41 & 2 \\
\hline Farklı türden örnekler çözmeli & Ö4, Ö11 & 2 \\
\hline Basit düzeyde anlatmalı & Ö12 & 1 \\
\hline Öğrenciyi merkeze almalı & Ö16 & 1 \\
\hline Bilinenden bilinmeyene doğru dersi anlatmalı & Ö40 & 1 \\
\hline İpuçlarıyla konunun keşfedilmesini sağlamalı & Ö21 & 1 \\
\hline Gereksiz bilgilerden kaçınmalı & Ö21 & 1 \\
\hline Diğer derslerle ilişkilendirmeli & Ö23 & 1 \\
\hline Ders sonu özetler yapmalı & Ö25 & 1 \\
\hline Anlaşılmayan konuları tekrar anlatmalı & Ö32 & 1 \\
\hline Sorgulayan bireyler yetiştirmeli & Ö34 & 1 \\
\hline Çözüm odaklı olmalıdır & Ö34 & 1 \\
\hline Öğrencilerin gelişim özelliklerini bilmeli & Ö39 & 1 \\
\hline Öğrencilerin sorularını cevapsız bırakmamalı & Ö9 & 1 \\
\hline Neler kazandırması gerektiğini bilmeli & Ö11 & 1 \\
\hline $\begin{array}{l}\text { Öğrencilerin matematiksel düşünme becerilerini } \\
\text { geliştirmeli }\end{array}$ & Ö11 & 1 \\
\hline
\end{tabular}


Öğretmen adaylarının meslek bilgisi teması altında görüşleri incelendiğinde en çok olarak öğrencilerin hazır bulunuşluk düzeylerinin bilinmesi ifadesinin bulunduğu belirlenmiştir. Materyal kullanma, matematiğe karşı olumsuz önyargıyı kaldırma ve konuya göre uygun yöntem tekniklerle konuyu anlatma da çoğunluk olarak belirtilmiştir. Bunun yanında sınıfa hâkim olma, derse aktif katılımı sağlama, soyut kavramları somutlaştırma, öğrencilerin kişisel özelliklerini bilme ve bireysel farklılıkları dikkate alma gibi özelliklerin de kullanıldığı görülmüştür. Basit düzeyde anlatma, öğrenciyi dikkate alma, dersi iyi organize etme, gereksiz bilgilerden kaçınma, çözüm odaklı olma, öğrencilerin gelişim özelliklerini bilme gibi ifadeler de birer öğretmen adayı tarafından belirtilmiştir. Bu kapsamda bazı öğretmen adaylarının görüşleri şu şekildedir.

"Her bir öğrencinin seviyesinin öğrenip ona göre orta bir şekilde dersi anlatmalıdır. Dersi tek düze anlatmamall, dersi farklı materyallerle desteklemeli, her ögrenciyi derste aktif hale getirmeli." (Ö45)

"Öğrencilerin çoğu matematikten korkmakta ve sevmemektedir. İyi bir matematik öğretmeni ise ögrencilerin bu korkularını ve önyargılarını yıkmalıdır." (Ö10)

"Matematik soyut bir derstir. Bu durumu kolaylaştırabilmek için konuları elinden geldiği kadar somutlaştırmalıdır. Bunun için de materyal kullanımı ve etkinliklere önem vermelidir. ” (Ö21)

“Öğrencilerin özelliklerini iyi bilmeli, onları çok iyi tanımalıdır. Ĕger bir öğrenciyi iyi tanımaz ve o ögrrenciden haberi olmazsa öğrenci dönemi boşa geçirmiş olur. Kalıcı ve etkili öğrenme gerçekleşmemiş olur. ” (Ö14)

“iyi bir matematik öğretmeni; matematiği ezber olarak değil kavramları tanımları doğayla özdeşleştirerek, mantığını sunarak, yeri geldiğinde öğrencinin hayatında kullanabileceği tarzda konuları anlatabilen ögretmen olmalıdır." (Ö49)

\section{SONUÇ, TARTIŞMA VE ÖNERILER}

Çalışmada, 4. sınıf matematik öğretmen adaylarının düşünceleri doğrultusunda matematik öğretmeninin sahip olması gereken özelliklerin neler olduğu araştırılmıştır. Yapılan görüşmeler ile elde edilen verilerin incelenmesi sonucunda, matematik öğretmenlerinin özellikleri derse yönelik tutumlar, kişisel özelikler, alan bilgisi ve mesleki bilgisi şeklinde isimlendirilen 4 tema olarak ifade edilmiştir.

Matematik öğretmenlerinin özelliklerinden derse yönelik tutumları teması altında öncelikle, matematik öğretmenlerinin dersi öğrencilere sevdirmeleri gerektiği tespit edilmiştir. Bu duruma benzer olarak Özdoğan ve Uyar (2012) çalışmalarında, öğrencilerin matematiği sevmelerinde öğretmenlerin önemli rolünün olduğu sonucuna varmışlardır. Ayrıca öğretmenlerin matematiği sevmelerinin ve öğretmenlerin matematiğin zor bir ders olduğunun farkında olmalarının matematik öğreniminde oldukça etkili olduğu sonucuna ulaşılmıştır. Bu nedenle öğrencilerin matematiği sevmediklerinin bilincinde 26 
olunarak yapılan bir eğitim öğretimin daha etkili olacağı ve kalıcı öğrenmelere olanak sağlayacağı ifade edilebilir. Öğrencilerin matematiğe karşı olumsuz önyargılarını ortadan kaldırmak için öğretmenlerinin bu tür noktalara dikkat etmelerinin kritik öneme sahip olduğu düşünülmektedir.

Kişisel özelliklerine yönelik tema kapsamında öncelikle matematik öğretmenlerinin öğrencilere kendilerini sevdirmeleri ve kendilerini geliştirmeleri gerektiği sonucuna ulaşılmıştır. Aynı zamanda öğrencilere arkadaş gibi davranma, iyi bir model olma, mesleğinin bilincinde olma, sabırlı ve anlayışlı olma gibi özelliklere de sahip olmalarının iyi bir eğitim ve öğretim açısından önemli olduğu görülmüştür. Bu özelliklerle benzer olarak Keklikçi ve Yılmazer (2013), öğrencilere samimi olarak yaklaşılmasının matematiğe yönelik olarak var olan korkuyu kaldıracağını belirtmişlerdir. Aynı zamanda Kısakürek (1985) başarılı bir öğretmenin öğrencilerine güven duyup ve yakınlık göstermesi gerektiği üzerinde durmuştur. Öğretmenlerin, öğrenciler tarafından model olarak alınması nedeniyle davranışlarında özenli davranmaları gerektiği tespit edilmiştir. Tanyolaç (1996), Kısaç (2002) ve Bindak (2005)'ın çalışmalarında da bu duruma paralel sonuçlar elde etmişlerdir. Bunun yanında mesleğini sevme, öğrencileri sevme ve anlama mesleğinin bilincinde olmalı, çağın gereksinimlerine ayak uydurabilmeli, sabırlı, anlayışlı olmalı, eleştiriye açık ve iyi bir gözlemci olmalı gibi ifadeleri de kullandıkları görülmüştür. Elde edilen sonuçlar doğrultusunda öğretmenlerin öğrencilere kendilerini sevdirmelerinin, kendilerini her yönde geliştirmelerinin, öğrencileri sevip arkadaş gibi davranmalarının, sabırlı ve anlayışı olmalarının matematik derslerinin yapılmasında derslerin zevkli geçmesine ve oldukça etkili olacağına olanak sağlayacağı düşünülmektedir.

Matematik öğretmenlerinin özelliklerine yönelik olarak belirlenen alan bilgisi teması kapsamında öğretmenlerin öncelikle alan bilgisine dayalı olarak alan bilgileriyle günlük yaşam arasında ilişki kurabilmesi gerektiği tespit edilmiştir. Matematik öğretmenlerinin konu bilgilerinin yüksek olması, matematik derslerinin günlük yaşamla ilişkilendirilmesine büyük oranda katk1 sağlayacağı vurgulanmıştır. Bu duruma paralel olarak Yenilmez ve Can (2006), Galbraith ve Stillman (2006) ile Yenilmez ve Uysal (2007)'da yapmış oldukları çalışmalarda benzer durumları belirtmişlerdir. Benzer olarak Özabacı ve Acat (2005) çalışmalarında ideal bir öğretmenin bilgilendirici olabilmesi için bilgili olması gerektiği üzerinde durmuşlardır. Ayrıca Philipp, Thanheiser ve Clement (2002) ve Yenilmez (2007) ise çalışmalarında alan bilgisinin önemi üzerinde durmuşlardır. Burada öğretmenlerin alan bilgisinin yanında var olan alan bilgilerini öğrencilere ifade etme ve anlatmalarının da etkili bir eğitim öğretim açısından kritik bir öneme sahip olduğu vurgulanmıştır. Bu doğrultuda öğretmen adaylarının alan bilgilerinin yeterli bir şekilde geliştirilmesinin ve bu bilgileri öğrencilere nasıl anlatacaklarına yönelik donanımlı öğretmenler olarak yetiştirilmeleri gerektiğinin önemli olduğu düşünülmektedir.

Meslek bilgisi temasında, öğretmen adaylarının en çok öğrencilerin hazır bulunuşluk düzeylerinin bilinmesi gerektiğini ifade ettikleri belirlenmiştir. Bunun yanında matematik dersinin materyallerle anlatılmasının etkili bir ders açısından önemli olduğu sonucuna ulaşılmıştır. DeRoche 
(1981) ve Margaret (2000) çalışmalarında matematiğin soyut bir ders olduğunu ve bu nedenle derslerin materyallerle işlenmesinin kalıcı öğrenmeler açısından etkili olacağını ifade etmişlerdir. Ayrıca matematiğe karşı var olan olumsuz önyargının kaldırılmasında öğretmenlerin oldukça önemli konumda olduğu tespit edilmiştir. Dersin uygun yöntem ve tekniklerle anlatılmasının hem olumsuz önyargıyı hem de kalıcı öğrenme açısından etkili olduğu sonucuna ulaşılmıştır. Benzer olarak Ural, Umay ve Argün (2008) çalışmalarında matematik dersinde başarılı olunması amacıyla çeşitli öğretim yöntem ve tekniklerinin kullanılmasının oldukça önemli olduğunu belirtmişlerdir. Bunun yanında öğretmenin sınıfa hâkim olarak derse aktif katılımı sağlamasının ve bireysel farklılıklara dikkat ederek derslerin işlenmesinin önemli olduğu vurgulanmıştır. Ayrıca matematik dersinin soyut kavramlardan oluşması nedeniyle soyut kavramların somutlaştırılmasının önemli olduğu sonucunu üzerinde durulmuştur.

Elde edilen sonuçlar doğrultusunda öğrencilerin matematiği sevmediklerinin bilincinde olunması gerektiği ve bu doğrultuda öğretmen ve öğretmen adaylarının bu konuda bilgilendirmek amacıyla seminerler verilmesinin oldukça faydalı olacağı düşünülmektedir. Ayrıca öğretmenlerin öğrencileri ve mesleğini sevmesi, çağın gereksinimlerine göre kendini geliştirmesi, öğrencilere karş1 arkadaş gibi davranıp sabırlı ve anlayışlı olması, öğrencilerin hazır bulunuşluluk düzeylerinin dikkate alınması, alan bilgisinin yanında nası öğretim yapacaklarının da oldukça etkili olduğu gibi durumların etkili bir eğitim öğretim için oldukça önemli olduğu belirlenmiştir. Bu nedenle öğretmen adaylarının derslerinde uygulamaya dayalı eğitim almalarının, daha donanımlı öğretmenler yetiştirme noktasında oldukça etkili olacağı düşünülmektedir.

\section{KAYNAKÇA}

Akkoyunlu, B. \& Kurbanoğlu, S. (2003). Öğretmen adaylarının bilgi okuryazarlığı ve bilgisayar özyeterlik algıları üzerine bir çalışma. Hacettepe Üniversitesi Eğitim Fakültesi Dergisi, 24, 1-10.

Alkan, H., Köroğlu, H. \& Başer, N. (1999). Ülkemizde matematik öğretmeninin yetiştirilmesi ve matematik öğretiminin amaçları. Dokuz Eylül Üniversitesi, Buca Ĕ̆itim Fakültesi Dergisi, 10, 522.

Arslan, S. \& Özpınar, İ. (2008). Öğretmen nitelikleri: İlköğretim programlarının beklentileri ve eğitim fakültelerinin kazandırdıkları, Necatibey Eğitim Fakültesi Elektronik Fen ve Matematik Ĕ̈itimi Dergisi, 2 (1), 38-63.

Baki, A. \& Gökçek, T. (2007). Matematik öğretmeni adaylarının benimsedikleri öğretmen modeline ilişkin bazı ipuçları. Hacettepe Üniversitesi Eğitim Fakültesi Dergisi, 32, 22-31.

Bindak, R. (2005). İlköğretim öğrencileri için matematik kaygı ölçeği. Firat Üniversitesi Fen ve Mühendislik Bilimleri Dergisi, 17(2), 442-448.

DeRoche, E. F. (1981). An administrator's guide for evaluating programs and personnel. Boston: Allyn and Bacon, Inc. 
Galbraith, P. \& Stillman, G. (2006). A framework for identifying student blockages during transitions in the modelling process. Zentralblatt für Didaktik der Mathematik, 38(2), 143-162.

Hiebert, J., Morris, A. K. \& Glass, B. (2003). Learning to learn to teach: An experiment model for teaching and teacher preparation in mathematics. Journal of Mathematics Teacher Education, 6 , 201-222.

Iossi, L. (2007). Strategies for reducing math anxiety in post-secondary students. In S. M. Nielsen \& M. S. Plakhotnik (Eds.), Proceedings of the Sixth Annual College of Education Research Conference: Urban and International Education Section (pp. 30-35). Miami, USA: Florida International University.

Keklikçi, H. \& Yılmazer, Z. (2013). İlköğretim öğrencilerinin matematik korku düzeyleriyle matematik öğretmenlerine yönelik görüşleri arasındaki ilişkinin belirlenmesi. Ë̆gitim ve Öğretim Araştırmaları Dergisi, 2(3), 198-204.

Kısaç, İ., (2002). Öğretmen öğrenci iletişimi sınıf yönetimi. Pegem yayınları, Ankara.

Kısakürek, M. A. (1985) Sınıf atmosferinin öğrenci başarısına etkisi. Eğitim fakülteleri üzerine bir araştırma. Ankara: A.Ü. Eğitim Bilimleri Fakültesi Yayınları

Kükey, E. \& Aslaner, R. (2017). İlköğretim matematik öğretmen adaylarının, iyi bir matematik öğretmeninin nasıl olması gerektiğine yönelik görüşlerinin incelenmesi. International e-Journal of Educational Studies (IEJES), 1 (1), 1-11.

Kyriacou, C. \& Coulthard, M. (2000). Undergraduates' Views of teaching as a career choice. Journal of Education for Teaching, 26, 117-126.

Lansdell, J. M. (1999). Introducing young children to mathematical concepts: Problems with new terminology. Educational Studies, 25(3), 327-333.

Margaret, M. B. (2000). Instructional materials development: A review of the IMD program. Past, Present, and Future. National Science Foundation, Arlington VA Directorate for Education and Human Resources.

Miles, M. B. \& Huberman, A. M. (1994). Qualitative data analysis (Second Edition). London: Sage Publications.

Özabacı, N. \& Acat, B. (2005). Öğretmen adaylarının kendi özellikleri ile ideal öğretmen özelliklerine dönük algılarının karşılaştırılması. Kuram ve Uygulamada Eğitim Yönetimi, 42, 211-236.

Özdoğan, E \& Uyar, M. (2012). Tübitak projesi: Aranızda matematiği sevmeyen var mı?. Eğitim ve Öğretim Araştırmaları Dergisi, 1(3), 64-69.

Philipp R., Thanheiser, E. \& Clement, L. (2002). The role of a children's mathematical thinking experience in the preparation of prospective elementary school teachers. International Journal of Educational Research, 37, 195-210.

Shulman, L.S. (1986). Those who understand: Knowledge growth in teaching. Educational Researcher, 15, 4-14. 
Shulman, L. S. (1987). Knowledge and teaching: foundations of the new reform, Harvard Educational Review, $57,1-22$.

Tanyolaç, G. (1996). 11-12 Yaş düzeyindeki öğrencilerin korku yaygınlıklarının bazı değişsenler açısından incelenmesi. Yayımlanmamış Yüksek Lisans Tezi, Hacettepe Üniversitesi Sosyal Bilimler Enstitüsü, Ankara.

Umay, A. (2004). Matematik eğitiminde değişim. http://www.matder.org.tr (erişim tarihi: 07.02.2017)

Ural, A., Umay, A. \& Argün, Z. (2008). Öğrenci takımları başarı bölümleri tekniği temelli eğitimin matematikte akademik başarı ve özyeterliğe etkisi. Hacettepe Üniversitesi Eğitim Fakültesi Dergisi, 35, 307-318.

Yenilmez, K. (2007). İlköğretim matematik öğretiminde karşılaşılan zorluklar ve nedenleri. XVI. Ulusal Eğitim Bilimleri Kongresi, 5-7 Eylül, Tokat-Türkiye.

Yenilmez, K. \& Can, S. (2006). Matematik öğretimi derslerine yönelik görüşler. On Dokuz Mayls Üniversitesi Ĕ̈itim Fakültesi Dergisi, 22, 47-59.

Yenilmez, K. \& Uysal, E. (2007). İlköğretim öğrencilerinin matematiksel kavram ve sembolleri günlük hayatla ilişkilendirebilme düzeyi, On Dokuz Mayıs Üniversitesi Eğitim Fakültesi Dergisi, 24, 8998.

Yıldırım, A. \& Şimşek, H. (2011). Sosyal bilimlerde nitel araştırma yöntemleri (8. Baskı). Seçkin Yayınc1lık, Ankara.

Yıldırım, K. (2006). Çoklu zekâ kuramı destekli kubaşık öğrenme yönteminin ilköğretim 5. sınıf öğrencilerinin matematik dersindeki akademik başarı, benlik algısı ve kalıcılı̆̆a etkisi. Yayımlanmamış Yüksek Lisans Tezi, Çukurova Üniversitesi Sosyal Bilimler Enstitüsü, Adana. 


\section{EXTENDED ABSTRACT}

\section{Introduction}

Nowadays, there is a need for individuals who constantly renew themselves, carry out life-long learning, follow developments, keep up with change and individuals who are able to produce knowledge while being a conscious consumer of information (Akkoyunlu \& Kurbanoğlu, 2003). In this context, today's people are thought to be productive, quick thinking, know of the knowledge they need to learn, people who are aware of the ways to learn more easily, who know themselves well, who can easily access to the information (Umay, 2004). In this context, it can be said that teachers have great duties in the training of individuals.

When the literature is examined, it is seen that the place of teachers is important in teaching mathematics. It is emphasized that the importance of teachers' need to focus on the knowledge they need to teach besides their field knowledge (Shulman, 1987; Özabacı \& Acat, 2005; Iossi, 2007). In this context, it is thought that examining the opinions of the pre-service teachers about the characteristics of the teachers should have, will contribute positively to the education process (Kükey \& Aslaner, 2017). For this reason, in this study it is examined what should be the characteristics of a good mathematics teacher according to the 4 th grade pre-service mathematics teacher.

\section{Method}

This study is designed as a case study of qualitative research methods as it is aimed to examine the current knowledge of the pre-service teachers. The study group of the study was determined by the easily accessible sampling method within the scope of purposive sampling method. The study group consisted of 50 mathematics pre-service teachers in the 4th grade of primary mathematics teaching program of a public university in the academic year 2017-2018. Among the pre-service mathematics teachers, 39 were female and 11 were male. The Pre-Service Mathematics Teacher Opinion Form was prepared in order to determine the views of the pre-service teachers. The data obtained after the study were analyzed with the help of content analysis. Pre-service teachers were coded as Ö1, Ö2 in the analysis of the data. The data obtained are coded under common themes.

\section{Findings, Discussion and Conclusion}

As a result of the analysis of the obtained data, the characteristics of a good mathematics teacher were determined under 4 themes according to the elementary mathematics teaching program 4th grade students. These themes are expressed as attitudes towards the course, personal attitudes, field knowledge and professional knowledge.

It was determined that mathematics teachers should to make lesson love the students firstly under the theme of attitudes towards mathematics teachers. Similarly to this situation, Özdoğan and Uyar (2012) concluded that the teachers have an important role in the students love of mathematics. In 
the context of the theme of personal characteristics, it was concluded that mathematics teachers should make students love themselves and improve themselves. At the same time the students act like friends, a good model, aware of the profession, to be has with features such as being patient and understanding has been shown to be important in terms of a good education and training. Similar to these characteristics, Keklikçi and Y1lmazer (2013) stated that the sincere approach to students would remove the fear for mathematics. It is determined that teachers should be able to establish a relationship between field information and daily life based on the field knowledge in the context of the field information theme determined for the characteristics of the mathematics teachers. It was emphasized that the high level of knowledge of mathematics teachers will contribute to the greatly to associating mathematics lessons' with daily life. Parallel to this situation, Yenilmez and Can (2006), Galbraith and Stillman (2006), Yenilmez and Uysal (2007) have stated similar situations in their studies. In this respect, it is considered that it is important that pre-service teachers are adequately developed the knowledge of the field and that they should be trained as teachers who will be able to explain this information to the students. It has been determined that students' readiness levels should be known within the context of professional knowledge. In addition to this, it is concluded that teaching mathematics with materials is important for an effective lesson. DeRoche (1981) and Margaret (2000) stated that mathematics was an abstract lesson in his studies, and therefore the processing of lessons with materials would be effective in terms of persistent learning. In addition, it was emphasized that it was important for the teacher to ensure the active participation of the class and to teach the lessons by paying attention to individual differences. In addition, it was emphasized that it was important to concretize abstract concepts due to the fact that mathematics lesson was composed of abstract concepts. 